\title{
Automated Fuel Design Optimization for High Flux Isotope Reactor Low Enriched Uranium Core Design
}

\author{
J. W. Bae, B. R. Betzler, D. Chandler, and G. Ilas* \\ Oak Ridge National Laboratory \\ 1 Bethel Valley Rd, Oak Ridge, TN 37830 \\ baej@ornl.gov,betzlerbr@ornl.gov,chandlerd@ornl.gov,ilasg@ornl.gov
}

\begin{abstract}
The low enriched uranium (LEU) conversion project for the High Flux Isotope Reactor (HFIR) requires that the converted core design perform as well as or better than the current high enriched uranium core design with respect to key performance metrics, such as isotope production, while maintaining sufficient safety margins. Various designs and fuel shapes have been explored in previous optimization studies. A suite of scripts has been developed for HFIR LEU design and analysis to simplify the reactor physics and thermal hydraulics (TH) analyses. The scripts include generating a high-fidelity 3D HFIR model to perform core depletion simulations with the SHIFT Monte Carlo code, performing an essential rod criticality search during depletion, parsing SHIFT output to determine HFIR key metrics, and performing TH analysis with the HFIR Steady-State Heat Transfer Code. Previously, these scripts were separated and required human interaction between simulation stages. These scripts have been modernized and integrated into a single Python package (the Python HFIR Analysis and Measurement Engine or PHAME) to streamline execution and avoid potential human error. After modernizing the suite of scripts into a single, automated workflow, the tool set was wrapped into an in-house metaheuristic optimization driver that enables different optimization methods, such as simulated annealing and particle swarm. The optimization driver samples a fuel shape, runs PHAME, calculates the cost function with the metrics returned from PHAME, and repeats those steps until it finds an optimal fuel shape. This work demonstrates the workflow of a comprehensive, automated reactor design study and how metaheuristic optimization methods can be leveraged to fine-tune a design parameter like fuel shape. This workflow of wrapping an optimization driver on a full-scale reactor analysis suite increases design and analysis efficiency.
\end{abstract}

KEYWORDS: optimization, LEU, HFIR

*Notice: This manuscript has been authored by UT-Battelle, LLC, under contract DE-AC0500OR22725 with the US Department of Energy (DOE). The US government retains and the publisher, by accepting the article for publication, acknowledges that the US government retains a nonexclusive, paid-up, irrevocable, worldwide license to publish or reproduce the published form of this manuscript, or allow others to do so, for US government purposes. DOE will provide public access to these results of federally sponsored research in accordance with the DOE Public Access Plan (http://energy.gov/downloads/doe-public-access-plan) 


\section{INTRODUCTION}

The High Flux Isotope Reactor (HFIR) is a high-flux, pressurized, light-water-cooled and -moderated, flux-trap-type research reactor at Oak Ridge National Laboratory (ORNL) (Fig. 1). The HFIR core consists of involute-shaped fuel plates placed within two regions of the reactor: the inner fuel element (IFE) and the outer fuel element (OFE). Currently, the fuel is a $93 \%{ }^{235} \mathrm{U}$ enriched dispersion fuel $\left(\mathrm{U}_{3} \mathrm{O}_{8}-\mathrm{Al}\right)$. A proposed low enriched uranium (LEU) fuel is $19.75 \%{ }^{235} \mathrm{U}$ enriched uranium silicide $\left(\mathrm{U}_{3} \mathrm{Si}_{2}-\mathrm{Al}\right)$ dispersion fuel. Inside the fuel plate, the fuel is surrounded by a filler material composed of aluminum; the IFE filler contains boron in the form of $\mathrm{B}_{4} \mathrm{C}$ [1].

The LEU conversion project for the HFIR requires the converted core design to perform as well as or better than the current high enriched uranium (HEU) core design with respect to key performance metrics, such as isotope production, while maintaining sufficient safety margins [2]. Although there are numerous metrics such as the flux at the cold source, the fast flux in the flux trap, and the cycle length [3], only two metrics, californium production (performance) and minimum burnout margin (safety), are investigated in this study. The californium production metric is the sum of ${ }^{252} \mathrm{Cf}$ produced in the flux trap curium targets. The minimum burnout margin is the ratio of burnout-to-nominal power, where the burnout power is the power at which the hot spot heat flux is equal to the burnout heat flux under flux-to-flow safety limit conditions [4].

The goal of this work is to investigate optimal fuel shapes for the IFE and OFE using a loosely coupled HFIR core neutronics and steady-state thermal hydraulics $(\mathrm{TH})$ analysis suite driven by a multivariate, multiobjective optimization algorithm [6]. Currently, this work is a proof of concept, and requires additional physical constraints to generate feasible designs.

Fuel shape is defined the radial gradient of the fuel meat thickness along the involute. Fine-tuning the fuel shape for optimized performance is difficult because reactor performance metrics and safety metrics generally conflict. Also, the metrics are sensitive to fuel shape, and there are two (IFE and OFE) fuel regions. Previously, followed an iterative process of performing an analysis, analyzing the data, and making adjustments to address the weak points of the iteration. For example, if the minimal burnout margin was lowest on the inner edge of the fuel, the shape was modified to have less fuel in the inner edge. However, this iterative approach was time-consuming and sometimes had unexpected results because the reactor is sensitive to perturbations in the fuel shape given its small size and high power density [7-9].

\section{PYTHON HFIR ANALYSIS AND MEASUREMENT ENGINE}

A HFIR fuel design study usually includes the following steps:

1. Define the design space:

- Fuel shape (IFE, OFE)

- Fuel design (center and symmetric radial fuel profile, axial contour, filler poison type and concentration)

2. Reactor physics input:

- Monte Carlo N-Particle code (MCNP) [10] input file generation (geometry definition only)

- Shift [11] input file generation (transport-depletion calculation) 


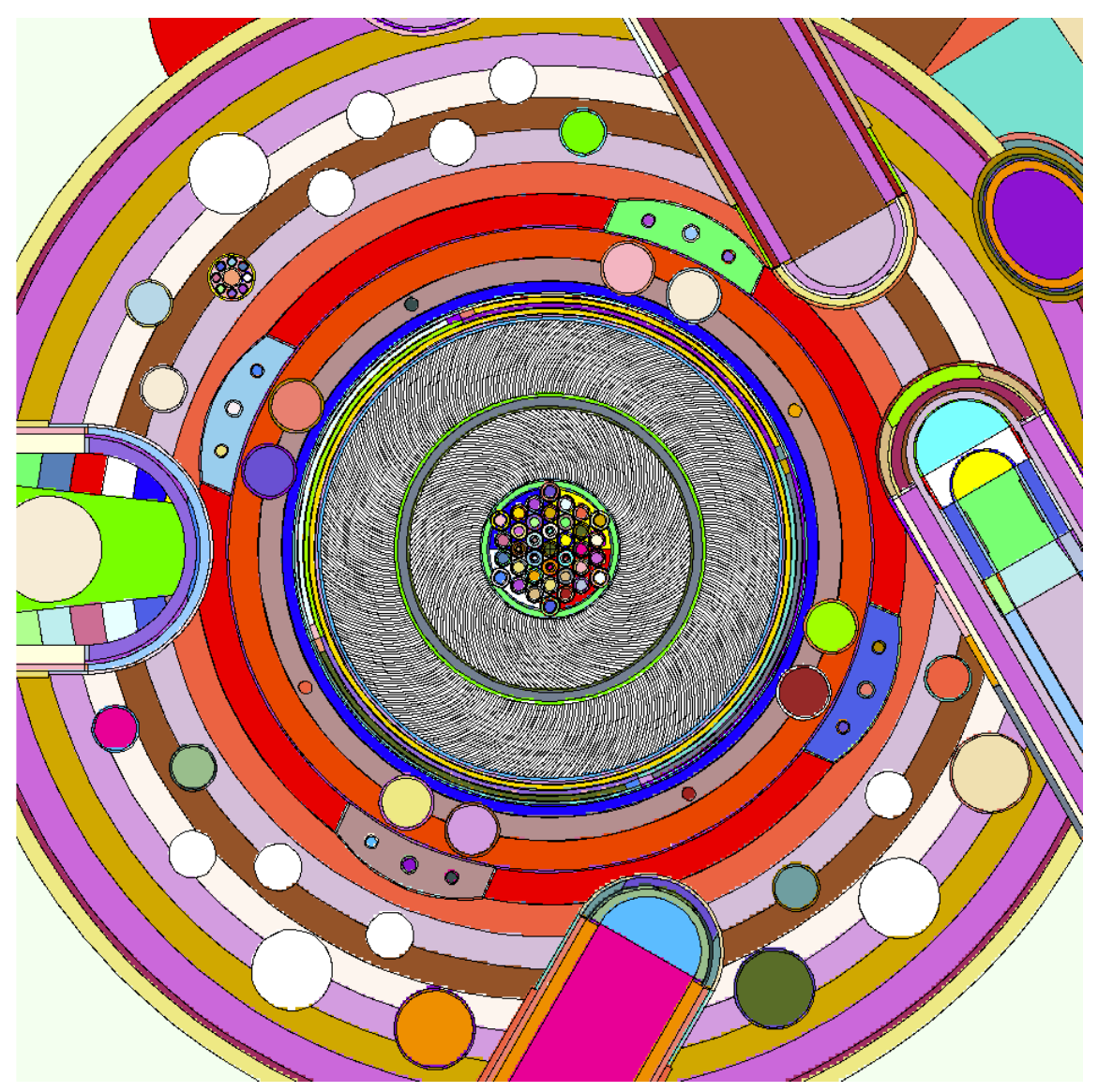

FIGURE 1. HFIRGeometry with a Representative Experiment Loading [5]. The colors denote different cells modeled in MCNP.

- Material definition

3. Reactor physics analysis:

- Shift calculation with depletion

- External script for critical control element position for each time step [12]

4. Steady-state TH input:

- Data from reactor physics output to HFIR Steady-State Heat Transfer Code (HSSHTC) input

5. Steady-state TH analysis

6. Display of results and repetition for optimization

The fuel shape is defined by discrete fuel meat thickness values along the fuel involute fitted with a sixth-degree polynomial with fixture points (i.e., the polynomial must intersect those points) for the continuous shape. Multiple fuel design options are available, but they add to the fuel fabrication complexity (Table I). In this study, the chosen fuel design has a fuel density of $4.8 \frac{\mathrm{g} U}{\mathrm{cc}}$, has fuel centered and symmetric within the plate, has no axial contour, and has no gadolinium in the filler.

Previously, the analysis steps were separated by analysis type and required multiple analysts in- 


\section{TABLE I. Fuel design options and benefits}

\begin{tabular}{|c|c|c|}
\hline Design option & Description & Benefit \\
\hline High-density silicide & $\begin{array}{l}\text { The density of uranium in the fuel } \\
\text { meat is } 5.3 \frac{\mathrm{g}}{\mathrm{cc}} \text { rather than } 4.8 \frac{\mathrm{g}}{\mathrm{cc}} \text {. }\end{array}$ & $\begin{array}{l}\text { Allows more fuel to be packed in- } \\
\text { side the core, increasing perfor- } \\
\text { mance and cycle time. This al- } \\
\text { lows for more optimal contouring } \\
\text { (fuel shaping) to enhance perfor- } \\
\text { mance and safety. }\end{array}$ \\
\hline Axial contour ('toe') & $\begin{array}{l}\text { The lowest } 1 \mathrm{~cm} \text { (out of } 55.88 \mathrm{~cm} \text { ) } \\
\text { of the fuel is linearly interpolated } \\
\text { from the top shape to a flat fuel } \\
\text { with reduced thickness. }\end{array}$ & $\begin{array}{l}\text { Because the coolant flows from } \\
\text { top to bottom in HFIR, the loca- } \\
\text { tion of limiting thermal margin is } \\
\text { at the outlet. By reducing fuel } \\
\text { mass on the bottom, outlet power } \\
\text { peaking is reduced. }\end{array}$ \\
\hline $\begin{array}{l}\text { Centered and symmet- } \\
\text { ric fuel zone }\end{array}$ & $\begin{array}{l}\text { The fuel meat is surrounded by } \\
\text { an equal amount of filler mate- } \\
\text { rial on each side (plates consist } \\
\text { of cladding, filler, fuel, filler, and } \\
\text { cladding instead of cladding, fuel, } \\
\text { filler, and cladding). }\end{array}$ & $\begin{array}{l}\text { Enhances heat transfer path from } \\
\text { fuel meat to coolant. }\end{array}$ \\
\hline $\mathrm{Gd}_{2} \mathrm{O}_{3}$ in IFE filler & $\begin{array}{l}\text { Gadolinium is added to suppress } \\
\text { IFE power peaking in the first } \\
\text { day(s). }\end{array}$ & $\begin{array}{l}\text { Increases the total fuel amount } \\
\text { while keeping safety margins in } \\
\text { the earlier cycle days (when mar- } \\
\text { gins are typically most limited) } \\
\text { lower. }\end{array}$ \\
\hline
\end{tabular}

teracting and transferring files [13-15]. To expedite the entire analysis process while eliminating the room for human error, all the analysis steps were connected by automating data processing and transfer between scripts (Fig. 2).

The modified Python HFIR Analysis and Measurement Engine (PHAME) module was tested with the previous workflow for an example case and yielded the same results. The automation of the entire design analysis suite resulted in two major benefits: (1) a quicker, more self-contained analysis process and (2) the ability to optimize using performance and safety metrics with an optimization driver.

\section{METHODS}

For the optimization, a multiobjective, multivariate optimization algorithm, the nondominated sorting genetic algorithm or NSGA-II [16] was used. This algorithm was implemented using the Python package Inspyred [17]. The metrics for which to optimize were the californium production 


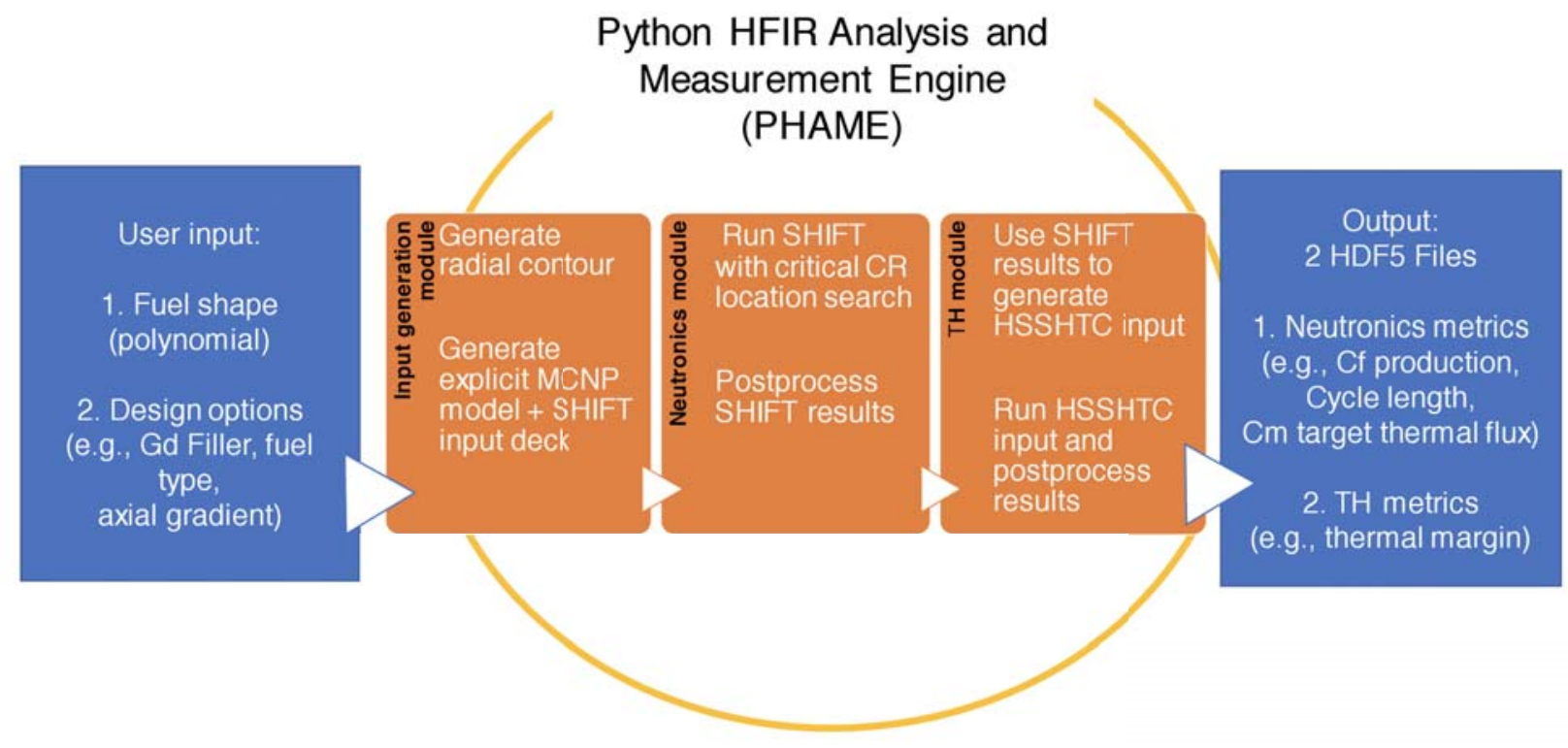

FIGURE 2. New Workflow of a More Automated HFIR Fuel Design Study.

$(\mu \mathrm{g})$ and minimum burnout margin (MW/MW). These two metrics were selected because they were observed to be the most limiting in previous design studies with silicide dispersion fuels [7-9]. The perturbed variables were the discrete fuel thickness points along the involute, which were then generated into a fuel shape by fitting a polynomial. The thickness points were bounded relative to the reference fuel shape, which is the most recent fuel shape iteration. The upper bound was 110\% of the reference fuel shape thickness points and the lower bound was $90 \%$ (Fig. 3). The bounds were implemented for accelerated convergence; however, these bounds may have prevented the algorithm from exploring more novel shapes.
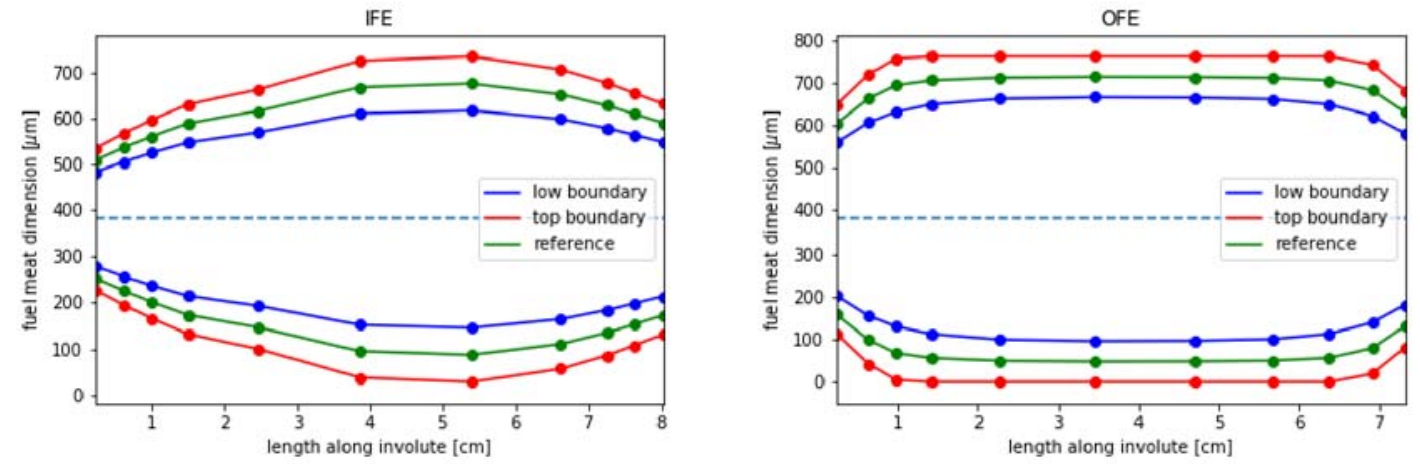

FIGURE 3. The Upper and Lower Bounds for the Optimization of Fuel Shape Were 110\% and $90 \%$ of the Discrete Fuel Thickness Points of the Reference Fuel Shape, Respectively.

Due to constraints in computational resources and time, only the first day of operation for each sample is simulated and compared. This is a fair simplification for the safety metric as with pre- 
vious experience with silicide fuels, since the most minimum burnout margins occur in the first day [18]. However, for the californium production rate, this simplification, although a good indicator of the full cycle performance, does not take into account the time variation of the production in the reactor because the californium production in the curium targets are relatively much lower in the first 6-10 days of operation, and rapidly increases as the "light" target inventory becomes "heavier".

The optimization driver sends the PHAME module its discrete thickness points, and PHAME converts those points into a fuel shape polynomial, performs the analyses, and returns the metrics to the driver. The driver then sorts the metrics and evolves its input samples every generation. For this study, an evolution generation consists of eight samples. This analysis was run on the ORNL internal cluster. The job was run with 4 nodes and 32 cores per node, for approximately 371 hours.

\section{RESULTS}

The results of the optimization show clear improvement between generations as well as an improvement from the reference fuel shape (Fig. 4). The samples that create the Pareto front dominate (i.e., outperform) the reference design.

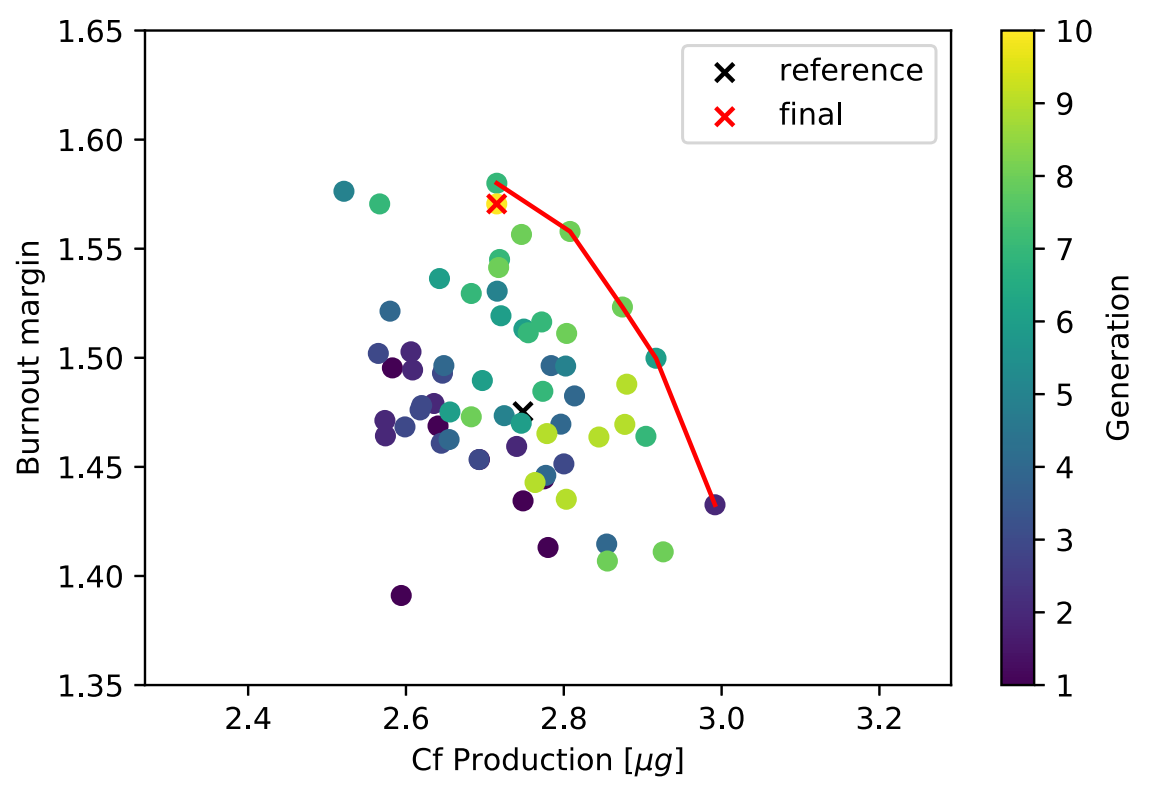

FIGURE 4. Evolution of first-day metrics with each generation for a low-density, centered and symmetric silicide fuel. The red line denotes the Pareto front. The red ' $x$ ' denotes the final shape metrics.

Fuel shape samples colored by generation (Fig. 5) show that the fuel shapes at higher generations overlap more because the successful samples pass on their traits (points) to the next generation. It should be noted that most of the fuel shapes cannot be fabricated, since they have a point of 
inflection. Post-processing the fuel shapes to filter out the shapes with a point of inflection, a final fuel shape is acquired (red line in Fig. 5).
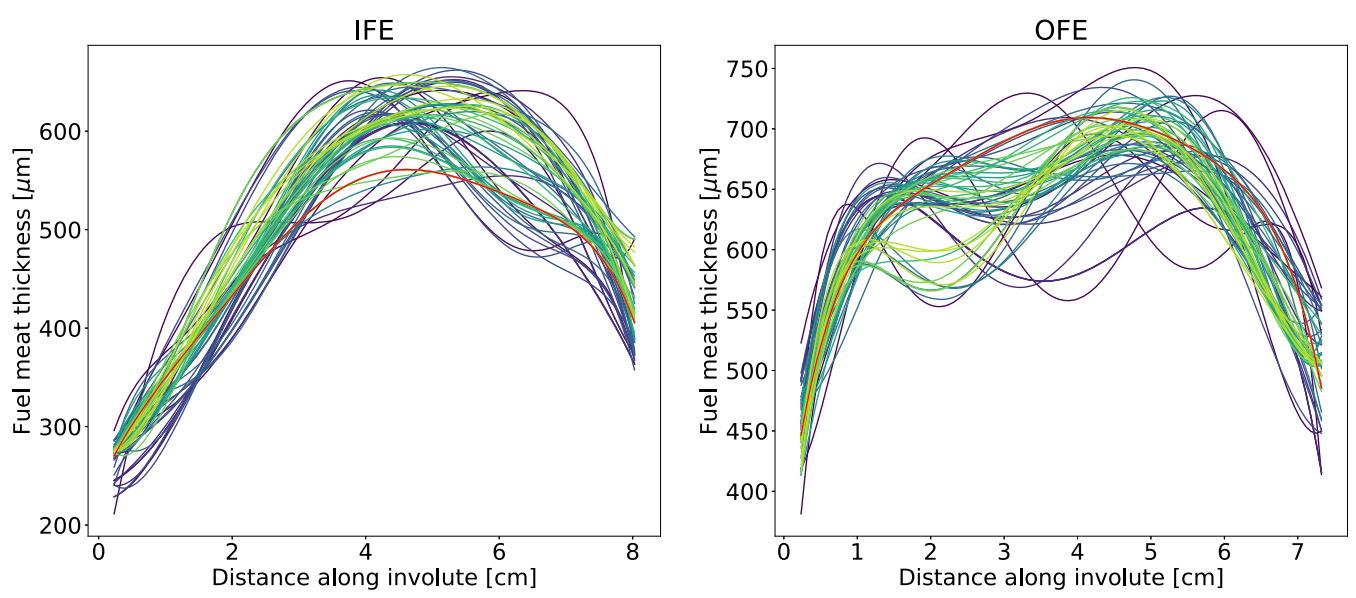

FIGURE 5. Evolution of fuel shape with each generation. Lighter colors denote higher generations. The shape converges to a smaller variance with successive generations. The red line is the final shape that does not have a point of inflection.

\section{SUMMARY}

We demonstrated an improved workflow for finding an optimized design of the LEU HFIR radial fuel shape. This process can be used to search for ranges of optimized metrics for a fuel design. This complex problem of optimizing fuel shape in a highly sensitive system was accomplished with little human effort through an automated analysis suite driven by an optimization algorithm [6]. The same process is applicable to different fuel designs with asymmetric fuel shapes and/or an axial contour.

Further improvements to the optimization problem definition would ensure that the fuel shape sampled by the algorithm takes into account fabrication processes (e.g., a point of inflection in the fuel shape is not fabricable). Also, with the data gathered in the optimization process, a statistical analysis of the fuel shape and reactor metrics may lend to insights in the quantitative relationship between the two.

\section{REFERENCES}

[1] R. D. Cheverton and T. M. Sims. "HFIR Core Nuclear Design." Technical Report ORNL4621, Oak Ridge National Lab. (1971).

[2] B. R. Betzler, D. Chandler, E. E. Davidson, and G. Ilas. "High-Fidelity Modeling and Simulation for a High Flux Isotope Reactor Low-Enriched Uranium Core Design.” Nuclear Science and Engineering, volume 187(1), pp. 81-99 (2017). URL https://doi.org/10.1080/00295639. 2017.1292090 . 
[3] G. Ilas, B. R. Betzler, D. Chandler, D. G. Renfro, and E. E. Davidson. "Key metrics for HFIR HEU and LEU models." Technical Report ORNL/TM-2016/581 (2016). URL http: //www.osti.gov/servlets/purl/1330553/.

[4] B. R. Betzler, D. Chandler, D. H. Cook, E. E. Davidson, and G. Ilas. "Design optimization methods for high-performance research reactor core design." Nuclear Engineering and Design, volume 352 (2019). URL http://www.sciencedirect.com/science/article/pii/ S0029549319301773.

[5] D. Chandler, B. Betzler, G. J. Hirtz, G. Ilas, and E. Sunny. "Modeling and Depletion Simulations for a High Flux Isotope Reactor Cycle with a Representative Experiment Loading." Technical Report ORNL/TM-2016/23, 1325434 (2016). URL http://www.osti.gov/servlets/ purl/1325434/.

[6] I. Variansyah, B. R. Betzler, D. Chandler, G. Ilas, and W. R. Martin. "A Metaheuristic Optimization Tool for High Flux Isotope Reactor Low-Enriched Uranium Core Design.”

[7] D. Chandler, B. R. Betzler, D. H. Cook, G. Ilas, and D. G. Renfro. "Neutronic and ThermalHydraulic Feasibility Studies for High Flux Isotope Reactor Conversion to Low-Enriched Uranium U3Si2-Al Fuel.” In Proc. PHYSOR 2018. Cancún, Mexico (2018).

[8] D. Chandler, B. R. Betzler, G. Ilas, D. H. Cook, and D. G. Renfro. "High Flux Isotope Reactor Low-Enriched Uranium Core Designs and Challenges." In Proc. ANTPC 2018. Wilmington, NC, USA (2018).

[9] D. Chandler, B. Betzler, D. Cook, G. Ilas, and D. Renfro. "Neutronic and thermal-hydraulic feasibility studies for High Flux Isotope Reactor conversion to low-enriched uranium silicide dispersion fuel." Annals of Nuclear Energy, volume 130, pp. 277-292 (2019). URL http: //www.sciencedirect.com/science/article/pii/S0306454919301069.

[10] C. J. Werner. "MCNP USERS MANUAL Code Version 6.2." User Manual la-ur17-29981, Los Alamos National Lab. (LANL), Los Alamos, NM (United States), Los Alamos, NM, United States (2017). URL https://laws.lanl.gov/vhosts/mcnp.lanl.gov/pdf_ files/la-ur-17-29981.pdf.

[11] T. M. Pandya, S. R. Johnson, G. G. Davidson, and T. M. Evans. "SHIFT: A Massively Parallel Monte Carlo Radiation Transport Package." (2015).

[12] B. R. Betzler, B. J. Ade, D. Chandler, G. Ilas, and E. E. Sunny. "Optimization of Depletion Modeling and Simulation for the High Flux Isotope Reactor." In Proc. $M \& C$ 2015. Nashville, TN, USA (2015).

[13] B. R. Betzler, D. Chandler, E. E. Davidson, and G. Ilas. "Design Optimization Studies for a High Flux Isotope Reactor Low-Enriched Uranium Core.” In Trans. Am. Nucl. Soc. (2017).

[14] B. R. Betzler, D. Chandler, D. H. Cook, E. E. Davidson, and G. Ilas. "High Flux Isotope Reactor Low-Enriched Uranium Core Design Optimization Studies." In Proc. PHYSOR 2018. Cancún, Mexico (2018).

[15] B. R. Betzler, D. Chandler, E. E. Davidson, and G. Ilas. "Optimized Design Performance Analysis Tools for a High Flux Isotope Reactor Low-Enriched Uranium Core." In Trans. Am. Nucl. Soc. (2018).

[16] K. Deb, A. Pratap, S. Agarwal, and T. Meyarivan. "A fast and elitist multiobjective genetic algorithm: NSGA-II." IEEE Transactions on Evolutionary Computation, volume 6(2), pp. 182-197 (2002).

[17] A. Garrett. "inspyred: Bio-inspired Algorithms in Python." (2017). URL http://aarongarrett. github.io/inspyred/. 
[18] D. Chandler, B. R. Betzler, J. W. Bae, D. H. Cook, and G. Ilas. "Conceptual Fuel Element Design Candidates for Conversion of High Flux Isotope Reactor with Low-Enriched Uranium Silicide Dispersion Fuel.” In Proc. PHYSOR 2020. Cambridge, United Kingdom (2020). 